\title{
Renal Magnesium Handling Is Not Subject to Developmental Programming
}

\author{
Saleh H. Alwasel ${ }^{a, b}$ Vandana Sahajpal ${ }^{c}$ Nick Ashton ${ }^{c}$ \\ ${ }^{a}$ Fetal Programming of Diseases Research Chair, ${ }^{b}$ Department of Zoology, College of Science, King Saud University, \\ Riyadh, Saudi Arabia; ${ }^{C}$ Faculty of Life Sciences, University of Manchester, Manchester, UK
}

\section{Key Words}

Magnesium • Fetal programming • Kidney $\cdot$ Calcium • Hypertension

\begin{abstract}
Developmental programming of hypertension, induced by maternal protein restriction, is associated with enhanced urinary excretion of sodium and calcium in the rat. Although calcium and magnesium are reabsorbed via different pathways, renal calcium excretion often parallels magnesium output. Accordingly, the aim of the current study was to assess magnesium handling in rats exposed to a low-protein (LP) diet in utero. Wistar rats were fed a control (18\%) or LP (9\%) diet throughout pregnancy; offspring were weaned onto standard rat chow and studied at 4 weeks of age. Renal clearance measurements were made in both volume expanded and euvolaemic anaesthetised rats; 24 -hour magnesium turnover was also assessed in conscious animals. Plasma and total body magnesium content were measured. Total $\left(\mathrm{U}_{\mathrm{Mg}} \mathrm{V}\right)$ and fractional excretion $\left(\mathrm{FE}_{\mathrm{Mg}}\right)$ of magnesium did not differ between control and LP rats under any of the experimental conditions. Neither plasma nor total body magnesium content differed between control and LP rats. Thus the hypercalciuria of LP rats is not mirrored by an increase in renal magnesium excretion. These data suggest that renal magnesium handling is not affected by developmental programming.

Copyright $\odot 2010$ S. Karger AG, Basel
\end{abstract}

\section{Introduction}

Developmental programming describes the phenomenon in which exposure to an adverse environment in utero has a life-long impact on the physiology of the offspring. Numerous studies in humans have shown that a poor maternal diet during pregnancy leading to a reduction in birth weight is associated with an increased risk of the child developing cardiovascular disease and diabetes mellitus in later life [1]. Similar effects can be induced in animal models by altering maternal food intake, facilitating the study of the underlying physiological mechanisms. One of the most common experimental approaches is to reduce dietary protein intake in the pregnant rat, which leads to a dose-related increase in offspring blood pressure [2].

A number of organs are affected by altered growth patterns in utero with the kidney being particularly susceptible to manipulation of the intrauterine environment. We [3] and others $[4,5]$ have shown that feeding pregnant rats a low-protein (LP) diet results in a 30-40\% reduction in the number of nephrons developed by the offspring. This reduction in renal capacity is associated with changes in the renin-angiotensin system $[3,6,7]$, and the renal handling of sodium [8] and calcium [9]. The latter is associated with a reduction in bone mineral content [10], bone mass, lower total serum calcium and inappropriately high concentrations of calcitropic hormones

Dr. Saleh Alwasel

College of Science, King Saud University

PO Box 2455

Riyadh 11451 (Saudi Arabia)

Tel. +966 550880848 ,E-Mail salwasel@ksu.edu.sa 
[9]. Such a pattern of impaired skeletal development in early life when peak bone mass is achieved represents a risk factor for osteoporosis in old age [11].

The regulation of calcium homeostasis is closely linked with that of magnesium. Hypocalcaemia is a common feature of hypomagnesaemia: even modest reductions in plasma magnesium can lead to marked reductions in serum calcium concentrations [12]. Magnesium deficiency is also linked to osteoporosis [13]; the mechanism is unknown but may involve a reduction in bone extracellular fluid $\mathrm{pH}$ leading to demineralisation [14]. Altered magnesium homeostasis may therefore contribute to the perturbation in calcium regulation seen in our earlier study in LP exposed rats [9].

The effect of maternal protein restriction on magnesium homeostasis is unknown. Accordingly, the aim of the current study was to determine renal magnesium handling in rats exposed to a LP diet in utero. As extracellular fluid volume expansion is known to affect magnesium reabsorption by the kidney [15], we have utilised two different approaches to assess renal function in vivo. In the first set of experiments, we used a standard constant infusion approach which leads to the expansion of extracellular fluid; in the second we used a servo-controlled fluid replacement system which allows the precise control of extracellular fluid volume. In order to overcome the potential confounding effect of anaesthesia, we also measured 24-hour magnesium turnover in conscious rats. Finally, we measured total body magnesium content to establish whether any changes in the small exchangeable pool of magnesium in the plasma are reflected in the larger bone stores.

\section{Methods}

All experiments were performed in accordance with the UK Animals (Scientific Procedures) Act 1986 and received local ethical approval.

Animals

Wistar rats (Harlan UK Ltd., Belton, UK) were paired in individual breeding cages and held in a room at $22-24^{\circ} \mathrm{C}$ with a $12 \mathrm{~h}$ light:12 $\mathrm{h}$ dark cycle. As soon as mating was confirmed by the presence of a sperm plug, the female's diet was switched from standard chow (Rat \& Mouse Standard Diet, Bantin \& Kingman Ltd., Hull, UK) to one which contained either $9 \%$ protein (LP) or $18 \%$ protein (control). The semi-synthetic diets were formulated as described previously [3]. On the day of birth, the dam's diet reverted to standard chow and the litter size was reduced to 8 animals. Male offspring were studied at 4 weeks of age.

$\mathrm{Mg}^{2+}$ Handling in Programmed

Hypertension
Renal Function - Conscious Animals

Four-week-old male rats (control $\mathrm{n}=14, \mathrm{LP} \mathrm{n}=11$ ) were housed individually in metabolic cages provided with stainless steel mesh bottoms and a urine collection pan underneath attached to a glass collection flask. Rats were kept in a thermoregulated room at 22$24^{\circ} \mathrm{C}$ and approximately $18 \%$ relative humidity, with a controlled $12 \mathrm{~h}$ light:dark period. Water and food $\left(0.096 \mathrm{mmol} \mathrm{Na}{ }^{+}, 0.179\right.$ $\mathrm{mmol} \mathrm{K}, 0.185 \mathrm{mmol} \mathrm{Ca}^{2+}, 0.074 \mathrm{mmol} \mathrm{Mg}^{2+}$ per gram) were provided ad libitum. One day was allowed for adaptation to the cage conditions followed by 5 consecutive days of urine collection. Cages and urine collection flasks were cleaned thoroughly with deionised water after the collection of urine. Once urine was collected, samples were centrifuged, weighed and stored at $4^{\circ} \mathrm{C}$. At the end of the experiment, animals were sacrificed humanely by stunning and decapitation to allow collection of trunk blood which was spun at 2,500 $\mathrm{g}$ for $10 \mathrm{~min}$. Plasma was removed and stored at $-20^{\circ} \mathrm{C}$ prior to analysis for $\mathrm{Mg}^{2+}$ concentration (see below).

Renal Function - Anaesthetised Animals

Inactin (thiobutabarbital sodium, $100 \mathrm{mg} / \mathrm{kg}$ i.p.) anaesthetised rats were prepared for renal clearance measurements. Briefly, a jugular catheter was implanted for the continuous infusion of $0.154 \mathrm{M} \mathrm{NaCl}$. A carotid catheter was implanted to allow continuous recording of arterial blood pressure, using a data acquisition system (PowerLab 800/s, ADInstruments, Hastings, UK), and withdrawal of blood samples. A catheter was also implanted in the urinary bladder to facilitate collection of urine. A tracheotomy was performed to assist breathing and a rectal probe was inserted to monitor body temperature, which was maintained at $37^{\circ} \mathrm{C}$ by means of a heated surgical table.

Animals were then divided at random into two groups. The first group of rats (control $n=12, \mathrm{LP} n=12$ ) received a continuous i.v. infusion of $0.154 \mathrm{M} \mathrm{NaCl}$ at $50 \mu \mathrm{lmin}^{-1} 100 \mathrm{~g}^{\text {body weight }}{ }^{-1}$ (volume expanded rats). The second group of animals (control $\mathrm{n}=15, \mathrm{LP} \mathrm{n}=15$ ) received an i.v. infusion of $0.154 \mathrm{M} \mathrm{NaCl}$ at a rate matched to spontaneous urine output (euvolaemic rats). This was achieved by means of a servo-controlled fluid replacement system which monitors urine flow rate over a defined period $(15 \mathrm{~min})$ and then adjusts a computer-controlled infusion pump to match the rate of infusion to urine output over the subsequent 15 -min period [16]. This prevents expansion of extracellular fluid volume and allows renal clearance measurements to be made in a euvolaemic state.

Following surgery, both groups of animals received a bolus of ${ }^{3} \mathrm{H}$-inulin $(4 \mu \mathrm{Ci}$, Amersham Biosciences UK Ltd., Little Chalfont, UK) via the jugular vein cannula. ${ }^{3} \mathrm{H}$-inulin was infused, as a marker of glomerular filtration rate, at $0.3 \mu \mathrm{Ci} / \mathrm{h}$ in all animals. For the first group of volume expanded rats, the ${ }^{3} \mathrm{H}$-inulin was simply added to the $0.154 \mathrm{M} \mathrm{NaCl}$ infusion; for the second group of fluid-balanced rats, ${ }^{3} \mathrm{H}$-inulin was infused via a second, slow $(1 \mathrm{ml} / \mathrm{h})$ infusion pump at a rate less than the spontaneous urine flow rate. All animals were allowed a 2-hour equilibration period after which urine samples were collected every $15 \mathrm{~min}$ for a further hour. A blood sample $(300 \mu \mathrm{l})$ was taken at $30 \mathrm{~min}$, mid-way through the urine collection period; a similar volume of $0.154 \mathrm{M}$ $\mathrm{NaCl}$ was replaced via the jugular catheter. Animals were sacrificed humanely at the end of the experiment. Urine and plasma samples were analysed for $\mathrm{Mg}^{2+}$ by atomic absorption spectroscopy (Solaar S Series, Thermo Elemental (Unicam Ltd.), Cam- 


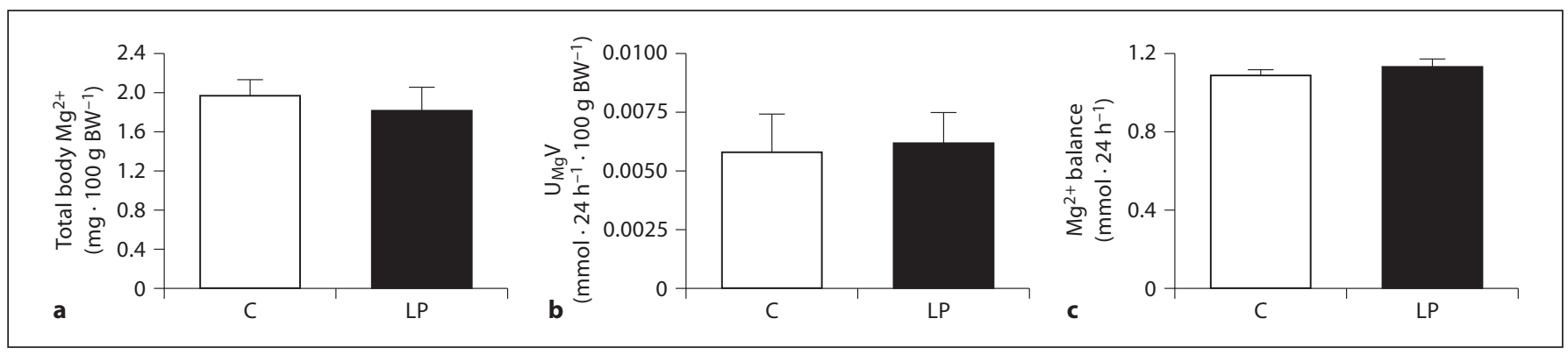

Fig. 1. Total body magnesium (a), urinary magnesium excretion rate $\left(U_{M g} V\right)(\mathbf{b})$ and magnesium balance (c) in conscious 4 -week-old control ( $\mathrm{C} ; \mathrm{n}=14$, open bars) and LP ( $\mathrm{n}=11$, solid bars) male rats held in metabolism cages for 5 days. Data are shown as the mean \pm SEM; statistical analysis was by the two-tailed t test.

bridge, UK); ${ }^{3} \mathrm{H}$-inulin was determined using a 1900CA Tri-Carb Liquid Scintillation Analyser (Canberra Industries, Meriden, Conn., USA) $\beta$-counter.

\section{Total Body Magnesium Content}

Control $(n=6)$ and LP $(n=6)$ rats were sacrificed by an overdose of Inactin (thiobutabarbital sodium), weighed and dried to a constant weight at $80^{\circ} \mathrm{C}$ in an oven (Griffin Oven, Griffin \& George Ltd., Wembley, UK) over 10 days. Dried carcasses were then transferred to aluminium oxide crucibles and ashed in a muffle oven at $675^{\circ} \mathrm{C}$ for $24 \mathrm{~h}$. The resulting ash was dissolved in concentrated nitric acid before further dilution in deionised water and the measurement of $\mathrm{Mg}^{2+}$ as described above.

\section{Statistical Analysis}

Data are shown as the mean \pm SEM. Statistical comparisons were by two-tailed t test or one-way ANOVA and Tukey's test, as appropriate (SPSS version 16.0, SPSS UK Ltd., Surrey, UK). Significance was assumed when $\mathrm{p}<0.05$.

\section{Results}

Body weight did not differ between control (111.2 \pm $3.0 \mathrm{~g}, \mathrm{n}=41)$ and $\mathrm{LP}(116.4 \pm 4.1 \mathrm{~g}, \mathrm{n}=38, \mathrm{p}=0.31)$ rats aged 4 weeks. However, mean arterial blood pressure, measured in the anaesthetised animals, was significantly higher in LP rats (control $n=27,86 \pm 4$ vs. $L P n=27,104$ $\pm 3 \mathrm{mmHg}, \mathrm{p}<0.001)$.

Plasma magnesium concentrations did not differ between control and LP rats (table 1). Extracellular fluid volume status had no effect on the plasma magnesium concentration of control animals $\left(\mathrm{F}_{2,40}=1.2, \mathrm{p}=0.3\right)$; however, volume status did affect magnesium concentration in LP rats $\left(\mathrm{F}_{2,37}=4.4, \mathrm{p}=0.02\right)$. The plasma magnesium concentration of volume-expanded LP rats was significantly lower than that of conscious LP rats $(\mathrm{p}<0.05)$.
Table 1. Plasma magnesium concentrations ( $\mathrm{mmol} / \mathrm{l})$ in 4 -weekold rats exposed to a maternal low protein diet in utero

\begin{tabular}{lll}
\hline & \multicolumn{2}{l}{ Plasma magnesium } \\
\cline { 2 - 3 } & control & low protein \\
\hline $\begin{array}{l}\text { Conscious rats } \\
\begin{array}{l}\text { Anaesthetised volume- } \\
\text { expanded rats }\end{array}\end{array}$ & $0.79 \pm 0.04(14)$ & $0.83 \pm 0.04(11)$ \\
Anaesthetised euvolaemic rats & $0.75 \pm 0.03(12)$ & $0.66 \pm 0.04^{*}(12)$ \\
\hline
\end{tabular}

Data are shown as the mean \pm SEM; the number of animals in each group is shown in parentheses. Statistical analysis was by one-way ANOVA and Tukey's post-hoc test.

${ }^{*} \mathrm{p}<0.05$ LP conscious vs. LP volume expanded.

Total body magnesium content did not differ between control and LP rats (fig. $1 \mathrm{a}, \mathrm{p}=0.6$ ). Urinary magnesium excretion (fig. $1 \mathrm{~b}, \mathrm{p}=0.85$ ) and magnesium balance (dietary intake - urinary excretion, fig. $1 c, p=0.28$ ) did not differ between conscious control and LP rats held in metabolism cages for 5 days.

During the acute renal clearance experiments, differences were seen in the magnesium excretion rates according to the extracellular volume status of the animals; however, LP rats did not differ from control animals under either condition (fig. 2a, c). Urinary magnesium excretion was 4-fold higher in volume expanded rats compared with euvolaemic animals $\left(\mathrm{F}_{3,53}=7.2, \mathrm{p}<0.001\right)$. Urine flow rates were also greater in volume expanded rats (control $\mathrm{n}=12,63.6 \pm 8.9 ; \mathrm{LP} \mathrm{n}=12,69.5 \pm 9.9 \mu \mathrm{l}$

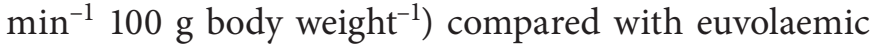
animals (control $\mathrm{n}=15,17.1 \pm 2.6 ; \mathrm{LP} \mathrm{n}=15,15.9 \pm 1.9$ $\mu 1 \mathrm{~min}^{-1} 100$ g body weight $\left.{ }^{-1}, \mathrm{~F}_{3,53}=21.9, \mathrm{p}<0.0001\right)$. 
Fig. 2 Urinary magnesium excretion rate $\left(\mathrm{U}_{\mathrm{Mg}} \mathrm{V}\right)$ and fractional excretion of magnesium $\left(\mathrm{FE}_{\mathrm{Mg}}\right)$ in anaesthetised volumeexpanded (a, b) control ( $\mathrm{n}=12$, open bars) and LP ( $\mathrm{n}=12$, solid bars) rats, and in euvolaemic (c, d) control $(\mathrm{C} ; \mathrm{n}=15$, open bars) and $\mathrm{LP}(\mathrm{n}=15$, solid bars) rats. Data are shown as the mean \pm SEM; statistical analysis was by one-way ANOVA and Tukey's test.

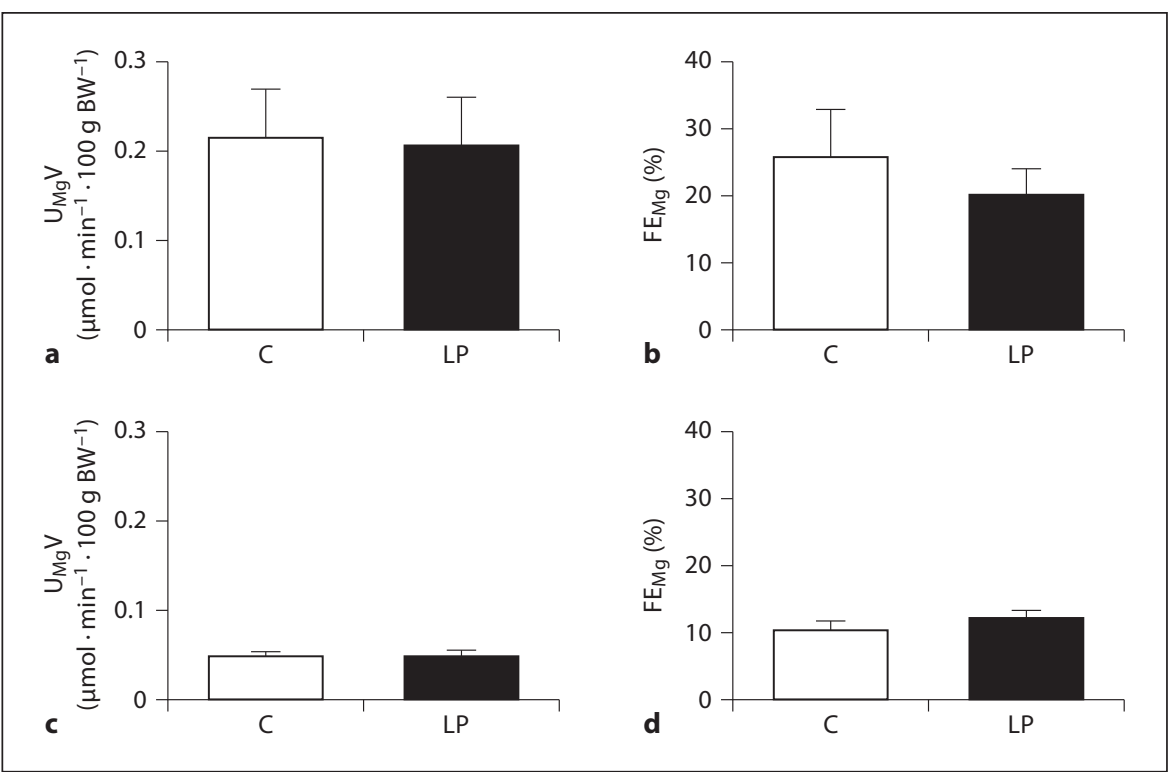

Fractional excretion of magnesium $\left(\mathrm{FE}_{\mathrm{Mg}}\right)$, which represents the proportion of filtered magnesium that is excreted, did not differ between control and LP rats irrespective of extracellular fluid volume status (fig. 2b, d). However, $\mathrm{FE}_{\mathrm{Mg}}$ was greater in control and $\mathrm{LP}$ rats under volume expanded conditions compared with euvolaemic animals $\left(\mathrm{F}_{3,53}=3.7, \mathrm{p}=0.017\right)$.

\section{Discussion}

This study shows that magnesium homeostasis is not affected by exposure to a LP diet in utero. Neither plasma nor total body magnesium content differed between control and LP rats. Similarly, the renal handling of magnesium did not differ between control and LP rats both under euvolaemic and volume expanded conditions. These data suggest that magnesium homeostasis is not influenced by developmental programming through maternal dietary manipulation. This is in marked contrast to calcium homeostasis which shows a number of important changes in the LP rat. These include a reduction in total plasma calcium concentration, increased urinary calcium excretion and a reduction in bone mass [9].

The majority of magnesium within the body is found in bone (60\%), with less than $2 \%$ in the extracellular fluid and only $0.3 \%$ found in plasma [17]. Despite the small quantity of magnesium in the plasma, magnesium homeostasis is regulated primarily by the kidneys. Approx- imately $70 \%$ of magnesium in the plasma is ultrafiltrable; $70-80 \%$ being free $\mathrm{Mg}^{2+}$ and the remainder complexed with filtrable anions such as oxalate, phosphate and citrate [18]. Only a small proportion of the filtered magnesium is reabsorbed by the proximal tubule (15\%), via a paracellular pathway, in contrast with calcium and other ions which are reabsorbed in greater quantities $(60 \%)$ in this part of the nephron.

Up to $70 \%$ of the filtered magnesium is reabsorbed in the loop of Henle. There is some evidence of reabsorption by the descending limb, but the majority of magnesium is reabsorbed in the thick ascending limb (TAL). In the rat, this is limited entirely to the cortical TAL (cTAL) with no reabsorption of magnesium, or calcium, in the medullary TAL (mTAL) [19]. Magnesium reabsorption across the CTAL is passive, via a paracellular route mediated by claudin-16 and claudin-19 [20,21]. It is driven by a positive lumen voltage which is maintained by active sodium reabsorption. Apical sodium uptake is mediated by the $\mathrm{Na}^{+}: \mathrm{K}^{+}: 2 \mathrm{Cl}^{-}$co-transporter (NKCC2 or BSC1) and basolateral efflux by the $\mathrm{Na}^{+}: \mathrm{K}^{+} \mathrm{ATPase}$. Claudin- 16 has been shown to mediate leakage of sodium back into the lumen, generating a lumen positive potential difference which drives magnesium (and calcium) reabsorption [22]. In this context it is interesting to note that expression of NKCC2 is increased in the LP rat $[8,23]$, which has led to the suggestion that sodium reabsorption is greater in LP animals [23]. However, we have shown that sodium excretion is increased, not decreased [8], which calls into 
question the functional activity of the excess NKCC2 expressed by LP rats. The current data lend further support to the notion that greater NKCC2 expression does not correlate with increased transport activity as magnesium excretion did not differ between LP and control animals.

The distal convoluted tubule (DCT) accounts for only $5 \%$ of magnesium reabsorption [24]; however, this segment plays an important role in determining urinary magnesium concentration as it is the last site of magnesium reabsorption by the nephron. Magnesium reabsorption by the DCT is an active transcellular process, separate from that which mediates calcium reabsorption [25]. The transient receptor potential melastatin subtype 6 (TRPM6), the only channel identified to date that mediates transepithelial magnesium transport [26, 27], is localised to the apical membrane of the early DCT [28]. Transepithelial calcium reabsorption via TRPV5, the renal epithelial calcium channel, occurs downstream in the late DCT and connecting tubule [29]. Regulation of TRPM6 is not fully understood, however $17 \beta$-oestrodiol [30] and epidermal growth factor [30] have been shown to act as magnesiotropic hormones which stimulate TRPM6. Raised intracellular magnesium can reduce TRPM6 activity [28] as can the receptor for activated Ckinase (RACK1) which is expressed predominantly in the kidney in the DCT [31]. RACK1 has been shown to play a role in magnesium-dependent suppression of TRPM6 activity, thereby preventing magnesium overload during reabsorption [32].
The DCT sodium chloride co-transporter NCC has been shown to influence TRPM6 expression. Gitelman's syndrome, an autosomal-recessive condition arising through mutations in NCC, is associated with sodium wasting and hypomagnesaemia [33]. NCC-knockout mice display hypomagnesaemia and renal magnesium wasting which are associated with down regulation of TRPM6 expression [34]. NCC expression has been reported to be increased in the LP rat [23], although we did not see any change at the mRNA level [8]. Whether this affects magnesium reabsorption by the DCT in the LP rat remains to be determined, but it seems unlikely given that there is no further change in tubular fluid magnesium content downstream of the DCT and that the final urinary excretion rate of magnesium does not differ between LP and control animals.

In conclusion, the current study shows that, unlike calcium [9] and sodium [8], renal handling of magnesium is not affected by exposure to a LP diet in utero. Despite increased expression of NKCC 2 in the LP rat TAL $[8,23]$, activity of the co-transporter does not seem to be increased; as a result there does not appear to be an increase in the driving force for magnesium reabsorption in this part of the nephron. Fine tuning of the final urinary magnesium content by the distal tubule also appears to be unaffected, suggesting that developmental programming does not alter expression or activity of TRPM6 or its regulators in the final part of the nephron.

\section{References}

1 Barker DJ, Bagby SP: Developmental antecedents of cardiovascular disease: a historical perspective. J Am Soc Nephrol 2005;16: 2537-2544.

-2 Langley SC, Jackson AA: Increased systolic pressure in adult rats induced by fetal exposure to maternal low protein diet. Clin Sci 1994;86:217-222.

$\checkmark 3$ Sahajpal V, Ashton N: Renal function and angiotensin $\mathrm{AT}_{1}$ receptor expression in young rats following intrauterine exposure to a maternal low-protein diet. Clin Sci (Lond) 2003;104:607-614.

4 Woods LL, Weeks DA, Rasch R: Programming of adult blood pressure by maternal protein restriction: role of nephrogenesis. Kidney Int 2004;65:1339-1348.

5 Langley-Evans SC, Welham SJ, Jackson AA: Fetal exposure to a maternal low protein diet impairs nephrogenesis and promotes hypertension in the rat. Life Sci 1999;64:965-974.
-6 Sahajpal V, Ashton N: Increased glomerular angiotensin II binding in rats exposed to a maternal low protein diet in utero. J Physiol 2005;563:193-201.

7 Woods LL, Ingelfinger JR, Nyengaard JR, Rasch R: Maternal protein restriction suppresses the newborn renin-angiotensin system and programs adult hypertension in rats. Pediatr Res 2001;49:460-467.

-8 Alwasel SH, Ashton N: Prenatal programming of renal sodium handling in the rat. Clin Sci (Lond) 2009;117:75-84.

9 Ashton N, Al-Wasil SH, Bond H, Berry JL, Denton J, Freemont AJ: The effect of a lowprotein diet in pregnancy on offspring renal calcium handling. Am J Physiol Regul Integr Comp Physiol 2007;293:759-765.
10 Mehta G, Roach HI, Langley-Evans S, Taylor P, Reading I, Oreffo RO, Aihie-Sayer A, Clarke NM, Cooper C: Intrauterine exposure to a maternal low protein diet reduces adult bone mass and alters growth plate morphology in rats. Calcif Tissue Int 2002;71: 493-498.

$\checkmark 11$ Cooper C, Walker-Bone K, Arden N, Dennison E: Novel insights into the pathogenesis of osteoporosis: the role of intrauterine programming. Rheumatology (Oxford) 2000; 39:1312-1315.

12 Fatemi S, Ryzen E, Flores J, Endres DB, Rude RK: Effect of experimental human magnesium depletion on parathyroid hormone secretion and 1,25-dihydroxyvitamin D metabolism. J Clin Endocrinol Metab 1991;73: 1067-1072.

13 Sojka JE, Weaver CM: Magnesium supplementation and osteoporosis. Nutr Rev 1995; 53:71-74. 
14 Swaminathan R: Magnesium metabolism and its disorders. Clin Biochem Rev 2003;24: 47-66.

$\checkmark 15$ Poujeol P, Chabardes D, Roinel N, De Rouffignac C: Influence of extracellular fluid volume expansion on magnesium, calcium and phosphate handling along the rat nephron. Pflügers Arch 1976;365:203-211.

16 Burgess WJ, Shalmi M, Petersen JS, PlangeRhule J, Balment RJ, Atherton JC: A novel computer-driven, servo-controlled fluid replacement technique and its application to renal function studies in conscious rats. Clin Sci 1993;85:129-137.

17 Satoh J, Romero MF: $\mathrm{Mg}^{2+}$ transport in the kidney. Biometals 2002;15:285-295.

18 Grimellec CL, Poujeol P, Rouffignia C: ${ }^{3} \mathrm{H}-$ inulin and electrolyte concentrations in Bowman's capsule in rat kidney: comparison with artificial ultrafiltration. Pflügers Arch 1975;354:117-131.

19 Mandon B, Siga E, Roinel N, de Rouffignac $\mathrm{C}: \mathrm{Ca}^{2+}, \mathrm{Mg}^{2+}$ and $\mathrm{K}^{+}$transport in the cortical and medullary thick ascending limb of the rat nephron: influence of transepithelial voltage. Pflügers Arch 1993;424:558-560.

-20 Konrad M, Schaller A, Seelow D, Pandey AV, Waldegger S, Lesslauer A, Vitzthum H, Suzuki Y, Luk JM, Becker C, Schlingmann KP, Schmid M, Rodriguez-Soriano J, Ariceta G, Cano F, Enriquez R, Juppner H, Bakkaloglu SA, Hediger MA, Gallati S, Neuhauss SC, Nurnberg P, Weber S: Mutations in the tightjunction gene claudin 19 (CLDN19) are associated with renal magnesium wasting, renal failure, and severe ocular involvement. Am J Hum Genet 2006;79:949-957.
21 Simon DB, Lu Y, Choate KA, Velazquez H, Al-Sabban E, Praga M, Casari G, Bettinelli A, Colussi G, Rodriguez-Soriano J, McCredie D, Milford D, Sanjad S, Lifton RP Paracellin-1, a renal tight junction protein required for paracellular $\mathrm{Mg}^{2+}$ resorption. Science 1999;285:103-106.

-22 Hou J, Shan Q, Wang T, Gomes AS, Yan Q, Paul DL, Bleich M, Goodenough DA: Transgenic RNAi depletion of claudin-16 and the renal handling of magnesium. J Biol Chem 2007;282:17114-17122.

23 Manning J, Beutler K, Knepper MA, Vehaskari VM: Upregulation of renal BSC1 and TSC in prenatally programmed hypertension. Am J Physiol 2002;283:202-206.

24 Quamme GA: Effect of furosemide on calcium and magnesium transport in the rat nephron. Am J Physiol 1981;241:340-347.

25 Xi Q, Hoenderop JG, Bindels RJ: Regulation of magnesium reabsorption in DCT. Pflügers Arch 2009;458:89-98.

26 Schlingmann KP, Weber S, Peters M, Niemann Nejsum L, Vitzthum $H$, Klingel K, Kratz M, Haddad E, Ristoff E, Dinour D, Syrrou M, Nielsen S, Sassen M, Waldegger S, Seyberth HW, Konrad M: Hypomagnesemia with secondary hypocalcemia is caused by mutations in TRPM6, a new member of the TRPM gene family. Nat Genet 2002;31:166170.

27 Walder RY, Landau D, Meyer P, Shalev H, Tsolia M, Borochowitz Z, Boettger MB, Beck GE, Englehardt RK, Carmi R, Sheffield VC: Mutation of TRPM6 causes familial hypomagnesemia with secondary hypocalcemia. Nat Genet 2002;31:171-174.
28 Voets T, Nilius B, Hoefs S, van der Kemp AW, Droogmans G, Bindels RJ, Hoenderop JG: TRPM6 forms the $\mathrm{Mg}^{2+}$ influx channel involved in intestinal and renal $\mathrm{Mg}^{2+}$ absorption. J Biol Chem 2004;279:19-25.

29 Loffing J, Loffing-Cueni D, Valderrabano V, Klausli L, Hebert SC, Rossier BC, Hoenderop JG, Bindels RJ, Kaissling B: Distribution of transcellular calcium and sodium transport pathways along mouse distal nephron. Am J Physiol Renal Physiol 2001;281: 1021-1027.

30 Groenestege WM, Hoenderop JG, van den Heuvel L, Knoers N, Bindels RJ: The epithelial $\mathrm{Mg}^{2+}$ channel transient receptor potential melastatin 6 is regulated by dietary $\mathrm{Mg}^{2+}$ content and estrogens. J Am Soc Nephrol 2006; 17:1035-1043.

>31 Cao G, Thebault S, van der Wijst J, van der Kemp A, Lasonder E, Bindels RJ, Hoenderop JG: RACK1 inhibits TRPM6 activity via phosphorylation of the fused $\alpha$-kinase domain. Curr Biol 2008;18:168-176.

32 Cao G, Hoenderop JG, Bindels RJ: Insight into the molecular regulation of the epithelial magnesium channel TRPM6. Curr Opin Nephrol Hypertens 2008;17:373-378.

33 Knoers NV, Levtchenko EN: Gitelman syndrome. Orphanet J Rare Dis 2008;3:22.

34 Nijenhuis T, Vallon V, van der Kemp AW, Loffing J, Hoenderop JG, Bindels RJ: Enhanced passive $\mathrm{Ca}^{2+}$ reabsorption and reduced $\mathrm{Mg}^{2+}$ channel abundance explains thiazide-induced hypocalciuria and hypomagnesemia. J Clin Invest 2005;115:16511658. 